OPEN ACCESS

Edited by: Marinella Coco,

Università di Catania, Italy

Reviewed by:

Selina Khoo,

University of Malaya, Malaysia

Si-Tong Chen,

Victoria University, Australia

*Correspondence: Amy Chan Hyung Kim kamy@fsu.edu

Specialty section:

This article was submitted to

Organizational Psychology, a section of the journal

Frontiers in Psychology

Received: 02 September 2021

Accepted: 20 January 2022

Published: 17 February 2022

Citation:

Kim ACH, Du J and Andrew DPS (2022) Changes in Physical Activity and Depressive Symptoms During COVID-19 Lockdown: United States Adult Age Groups.

Front. Psychol. 13:769930. doi: 10.3389/fpsyg.2022.769930

\section{Changes in Physical Activity and Depressive Symptoms During COVID-19 Lockdown: United States Adult Age Groups}

\author{
Amy Chan Hyung Kim*, James Du and Damon P. S. Andrew \\ Department of Sport Management, Florida State University, Tallahassee, FL, United States
}

This study investigates: (1) the changes in three major health-related factors-physical activity, non-physical-activity health behavior (i.e., diet quality, alcohol consumption, smoking, sleep quality), and depressive symptoms, and (2) how changes in physical activity were associated with changes in one's depressive symptoms among young adults, middle-aged adults, and older adults while controlling non-physical-activity health behavior and sociodemographic characteristics among young, middle-aged, and older adults before and after the COVID-19 outbreak lockdown in the United States. A total of 695 participants completed an online questionnaire via MTurk, and participants were asked to recall their physical activity, depressive symptoms, and non-physicalactivity health behavior status in January and May of 2020. The IPAQ-SF was used to evaluate individuals' physical activity, while the CES-D-10 was used to assess depressive symptoms. Covariates included non-physical-activity health behavior and sociodemographic factors. A Bayesian significance testing of changes was used to examine significant changes in physical activity, non-physical-activity behavior, and depressive symptoms in each age group while Bayesian regression analysis was employed to examine how the changes in physical activity were associated with respondents' depressive symptoms while controlling for individual NHB and sociodemographic characteristics. The results showed that the participants tended to maintain their physical activity levels after the lockdown despite significant increases in sitting time among young and older adults. Decreases in moderate physical activity frequency were associated with a higher level of depressive symptoms $\left(R^{2}=17.1 \%\right)$. Although young and middle-aged cohorts experienced fewer differences in depressive symptoms compared to their counterparts in the older group, we found no significant heterogeneity effects in the relationships of interest across all age groups. Considering different influences of physical activity on depressive symptoms depending on different levels of activity and ages, more randomized clinical trials with program-based intervention studies should be conducted with different physical activity programs for different age populations.

Keywords: COVID-19, physical activity, health behavior, mental health, depressive symptom 


\section{INTRODUCTION}

Since the COVID-19 outbreak, non-pharmaceutical public health interventions, such as shelter-in-place orders, social distancing, and isolation, have been implemented widely worldwide. Although quarantine is the best option to stop spreading the coronavirus (Islam et al., 2020), the collateral effects of quarantine are still not known very well (Jimenez-Pavon et al., 2020). Even though the level and timing of these restrictions varied from county to county, and state to state, almost all states of the United States except for Arkansas, Iowa, Nebraska, and North Dakota, issued stay-at-home orders, forcing people to stay home as much as they can to prevent the spread of COVID19 since March 2020 (Elassar, 2020; Putt, 2020). This increased isolation has spurred noticeable lifestyle changes (Du et al., 2021). Among many changes, the present study focuses on three significant health-related changes: changes in physical activity (PA), non-physical-activity health behavioral patterns (NHB; i.e., diet quality, alcohol consumption, smoking, sleep behavior), and depressive symptoms (DS) among young (18-39 years old), middle-aged ( $40-59$ years old), and older adults ( 60 years old and older) in the United States.

There are two different tales about the lockdown effect resulting from COVID-19. On one hand, due to the stay-athome orders and social isolation/distancing guidelines, many opportunities to be physically active were interrupted, leading to decreased levels of PA and increased sedentary behavioral patterns, including more screen and sitting times (Hall et al., 2020; Hammami et al., 2020), poorer diet quality, increased alcohol consumption and smoking, and irregular sleep quality (Mattioli et al., 2020a,b; Patwardhan, 2020; United Nations, 2020). More time spent outdoors is well-known to associate with higher levels of PA and lower levels of sedentary behavior (Schaefer et al., 2014; Eigenschenk et al., 2019). Increased time spent indoors after the COVID-19 confinement is expected to result in decreased levels of PA among the public (Woods et al., 2020). Few empirical studies have supported this expectation for a decrease in PA levels. Lopez-Bueno et al. (2020) reported a $20 \%$ decrease in weekly PA levels among Spanish Adults, while male participants over the age of 42 without a university degree had the greatest reduction. Yamada et al. (2020) found a significant decrease in PA levels among older adults (65-84 years old) in Japan in April 2020 compared to January 2020. The social confinement due to COVID-19 may result in unhealthy behaviors in that socially isolated and lonely individuals tend to have less favorable lifestyles, including poor nutritional habits and increased risk behaviors such as smoking or alcohol consumption (Loucks et al., 2006; Grippo et al., 2007; Mattioli et al., 2020b). In regard to nutritional habits, the COVID-19 outbreak may have forced the public to buy more packaged and long-life food rather than fresh food, resulting in an unhealthy diet and a reduced intake of antioxidants. Moreover, the lack of emotional support from one's social network, friends, and family is significantly associated with stress-driven alcohol consumption (Mattioli et al., 2020a) and an increased level of smoking among smokers, as well as increased relapses among ex-smokers (Patwardhan, 2020). Historically, disease-related quarantines lead to a high prevalence of psychological distress, anxiety and stress (DiGiovanni et al., 2003; Hawryluck et al., 2004; Lee et al., 2005). During the COVID-19 pandemic, several studies consistently reported that poorer psychological well-being and mental health was present compared to the pre-COVID-19 era due to financial-related stress from insecurity and financial losses (Purtle, 2020), social isolation (Banerjee and Rai, 2020; Golechha, 2020; Pelizza and Pupo, 2020), confusion from conflicting messages from authorities and media platforms (Pfefferbaum and North, 2020), unpredictability, uncertainty, and seriousness of the disease (Zandifar and Badrfam, 2020), high levels of fear and panic behavior such as stockpiling of resources (Mattioli et al., 2020b; Shigemura et al., 2020), or poor perceived health (Wang et al., 2020).

On the other hand, thanks to more free time resulting from work-from-home trends, people may spend more time on their leisure activities, including physical activity, gardening, or Do-It-Yourself (DIY) projects. During the lockdown, Roberts (2020) found that people with additional free time increased exercises such as walking, jogging, running, and cycling despite the shutdowns of sport facilities and sport events. However, the author noted that this increased time spent being physically active after the pandemic lockdown might be mostly by those who already partake in habitual regular exercises, recreational activities, and physical activities. The results also reported less alcohol consumption, except among heavy drinkers before the lockdown (Alcohol Change UK, 2020; CGA, 2020). In terms of sleep quality, it is expected that social isolation, disruption of daily life, greater work and family stress, excessive screen time, and stress-related fatigue resulting from the pandemic may negatively affect sleep quality (Sleep Foundation, 2020). Interestingly, several studies found that even though sleep duration was increased during the COVID-19 lockdown (Blume et al., 2020; Roberts, 2020), sleep quality was reduced (Blume et al., 2020; Fu et al., 2020; Pinto et al., 2020; Wright et al., 2020).

We identified three major research gaps in the studies of changes in PA, NHB, and DS after the COVID-19 quarantine. First, there is a lack of empirical evidence to confirm the (un)changes after the COVID-19 lockdown. Even though several scholars expected lower PA levels, poorer NHB, and more DS due to the COVID-19 confinement, these ideas were mostly experience-based commentaries without any empirical evidence (Rajkumar, 2020). Among the very few empirical studies based on COVID-19 data, Callow et al. (2020) found a negative association between levels of PA and levels of DS among adults over the age of 50 in North America. However, the study did not consider the potential existence of (un)changes before and after the COVID-19 quarantine. Second, scholars have overlooked the different population characteristics among adults-especially age-when examining the association between PA, NHB, and DS after COVID-19. For instance, Stephens (1988) found that the association between physical activity and mental health was stronger among younger adults (20-39 years old) compared to middle-aged/older adults (40 years and older). Furthermore, Fukukawa et al. (2004) found that, while there was a significant relationship between the levels of daily walking activity and DS among older adults (65-79 years old), no significant relationship 
was found among middle-aged adults (40-64 years old). In the same context, even though several studies identified age as a crucial factor in regard to the relationship between the levels of PA, NHB, and DS (Roberts, 2020), post-pandemic studies in this area have not considered the age effect (Lopez-Bueno et al., 2020). Lastly, there is a lack of relational studies regarding changes after the COVID-19 pandemic. That is, even though a number of studies have confirmed that individual DS is predicted by one's PA in general, no studies investigated how changes in PA may predict changes in DS among adults after the COVID-19 pandemic.

Taken together, to fill these gaps, the aims of this study are to investigate (1) the changes in three major health-related factors (i.e., PA, NHB, and DS) and (2) how changes in PA predict changes in one's DS while controlling NHB and personal characteristics among young adults, middle-aged adults, and older adults before and after the COVID-19 lockdown in the United States.

\section{MATERIALS AND METHODS}

\section{Participants and Study Design}

Respondents were recruited via Amazon Mechanical Turk (MTurk), a crowd-sourcing platform where individuals complete paid tasks for various organizations. The platform has been used frequently as a data collection method in health and medical research (Ranard et al., 2014; Mortensen and Hughes, 2018). The benefits of using MTurk include higher reachability, higher reliability, and higher completion rate (Mason and Suri, 2012; Rouse, 2015; Smith et al., 2015; Hauser and Schwarz, 2016). Three different survey pools based on the different non-institutionalized, United States resident, age groups were created: young (18-39 years), middle-aged (40-59 years), and older (60 years and older) (Frayer et al., 2017). The survey was conducted in the first week of June of 2020. After obtaining consent, respondents were directed to Qualtrics to answer screening questions about the participant's United States residency and age. We also included one attention question in the middle of the questionnaire (i.e., to continue with the survey, please select "Somewhat agree"). The current study was cross-sectional and based on a retrospective recall using a twowave setup. The participants who passed the screening questions were directed to a questionnaire in which the participants were asked to recall their PA, DS, and NHB in January. Then, the same questions about their PA, DS, and NHB in May of 2020 were asked. The platform provides the ability to use a response validation function that alerts a respondent about questions they may have missed in each panel so that the participant can answer every question before they can proceed to the next panel of the survey. This procedural remedy eliminates missing values in the dataset. Among 865 recorded responses who passed the screening questions, a total of 170 responses ( 55 young, 79 middle-aged, 36 older adults), which failed to pass the attention question, were excluded. In total, 695 responses ( $n_{\text {young }}=264, n_{\text {middle-aged }}=234$, and $\left.n_{\text {older }}=197\right)$ were included for further analysis. As shown in visualization in Figure 1, survey respondents emanated from all 48 contiguous states with the exception of four states in the Midwest, including Montana, Wyoming, South Dakota, and Nebraska. Notably, COVID-19 least impacted these rural communities in the Midwest in the early period of the pandemic (Zylla and Hartman, 2020), leaving us a reasonable representative sample frame for conducting the subsequent statistical analyses. This study protocol was approved by the Institutional Review Board at Florida State University (ID: STUDY00001406).

\section{Measures \\ Personal Characteristics}

A total of 8 items were included for measuring the sociodemographic characteristics of age, marital status, household income, education, occupation, height, weight, and zip code. We also computed an individual's BMI using the reported height and weight.

\section{Physical Activity}

Self-reported PA levels of January 2020 and May 2020 were assessed using the International Physical Activity Questionnaire-Short Form (IPAQ-SF), a validated measurement tool for PA used various adult population surveys (Lee et al., 2011). The questionnaire included seven items to record the frequency and duration of four different levels of weekly physical activities-vigorous activity (e.g., aerobics or heavy lifting), moderate activity (e.g., leisure cycling or doubles tennis), walking, and sitting as of January 2020 and May 2020, respectively.

\section{Non-physical-Activity Health Behavior}

With acceptable validity and reliability, we used four items to evaluate one's diet quality, including daily intakes of fruit and vegetables and weekly intakes of fast food and soft drinks (Oftedal et al., 2019). Alcohol consumption was assessed by the validated 3-item AUDIT Alcohol Consumption Questions (AUDIT-C) (Bush et al., 1998; Bradley et al., 2007; Barry et al., 2015), including questions about frequency and intensity of regular drinking and heavy drinking (e.g., "How often did you have a drink containing alcohol; How many drinks did you have on a typical day when you were drinking"). Smoking status was assessed by the validated 8-item Fagerstrom Test for Nicotine Dependence (FTND) (Heatherton et al., 1991; Hudmon et al., 2005), including frequency, amount, and dependency of smoking (e.g., "How soon after waking do you smoke your first cigarette"; "How many cigarettes a day do you smoke"; "Do you smoke even if you are sick in bed most of the day"). Sleep quality was measured by 3 items from the validated Pittsburg Sleep Quality Index (PSQI), which includes average daily hours of sleep, overall sleep quality, and sleep latency (e.g., "How would you rate your sleep quality overall"; "How many hours of actual sleep did you get at night"; "How long in minutes does it usually take you to fall asleep each night") (Buysse et al., 1989; Carpenter and Andryknowski, 1998; Grandner et al., 2006). Overall sleep quality ranged from $1=$ very good to $4=$ very bad. Similar to IPAQ and CES-D-10, the respondents answered the two sets of questions(diet quality, AUDIT-C, FTND, and PSQI) for both the January 2020 and May 2020 timeframes. 


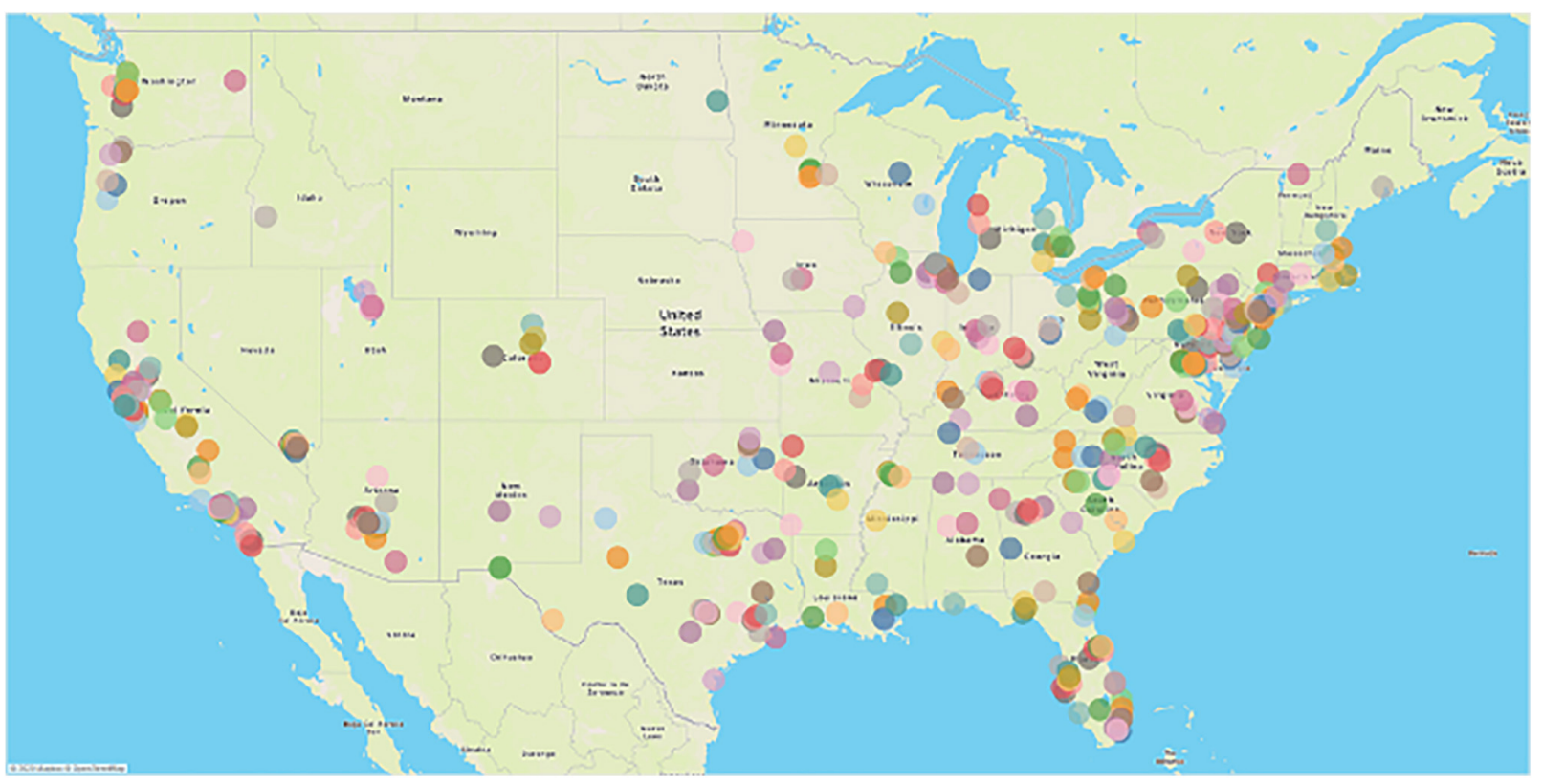

FIGURE 1 | Visualization of zip code analysis of survey respondents. Color represents different zip codes in the 48 contiguous states in the United States.

\section{Depressive Symptoms}

The Center for Epidemiologic Studies Depression Scale (CES-D10) was adopted to assess one's depressive symptoms (Andresen et al., 1994). This 10 -item questionnaire has been widely validated and used in studies of all age groups of adults (Noh et al., 2015; Wolanin et al., 2016; Mohebbi et al., 2018). The items reflect the feelings of the respondents (e.g., "I had trouble keeping my mind on what I was doing"; "I felt hopeful about the future"), and each item is ranged from $0=$ rarely or none of the time (less than 1 day per week) to $3=$ most or all of the time (5-7 days per week). The respondents answered 10 items for January 2020 and 10 items for May 2020, respectively. A compound score was generated by calculating the sum of 10 items. While a higher score indicates a higher level of DS, an individual with a score equal to or greater than ten was considered as depressed as previously recommended (Björgvinsson et al., 2013).

\section{Bayesian Analyses}

First, for testing significant changes in PA, NHB, and DS in each age group, we employed Bayesian significance testing of changes in $\mathrm{R}$ using the WinBUGS package (Sturtz et al., 2005). The Bayesian approach is less sensitive to the influence associated with missing values and does not require asymptotic assumptions. It is also computationally inexpensive to generate posterior distributions based on observed changes using the Markov Chain Monte Carlo (MCMC) algorithm (Baker et al., 2019). The goal was to examine if the predicted posterior credible intervals contain the value of zero, inferring no significant changes in a parameter were likely to be observed in a given age group at the population level.

Next, a Bayesian regression analysis was employed to examine how the changes in PA was associated with the changes in respondents' DS while controlling for individual NHB and personal characteristics. We used uniform distributions in the Bayesian significance testing of changes and employed baseline distributions of each parameter in January of 2020 as informative priors in the Bayesian regression model.

\section{Robustness Checks With Machine Learning}

To justify the robustness of regression results, machine learning analyses, including Random Forests (RF), Support Vector Machine (SVM), and Naïve Bayes (NB), were performed in Python. Machine learning techniques provide a repertoire of promising analytical strategies to validate if significant predictors identified from the regression analysis can improve the prediction accuracy of depression as a binary mental health outcome. Consistent with recommendations from machine learning literature, we used an 80:20 split to form training and testing datasets and employed Gini decrease (GD) and information gain (IG) to determine the variable importance (Breiman, 2001; Steinwart and Christmann, 2008). Finally, three confusion matrices were generated to assess the performance of machine learning models regarding the prediction accuracy.

\section{RESULTS}

Descriptive statistics of respondents are displayed in Table $\mathbf{1}$, and the baseline averages of the included parameters are presented in Table 2. Roughly $60 \%$ of respondents were male, and a majority of participants were Caucasian (70.20\%), well-educated (74.8\% possessed a 4 -year college or more advanced degrees), and lived in a typical middle-class family with annual household 
TABLE 1 | Descriptive statistics of sample demographic profiles.

\begin{tabular}{|c|c|c|c|c|}
\hline Age groups & Parameter & Mean/Mode ${ }^{\dagger}$ & Frequency & Percent \\
\hline \multirow[t]{7}{*}{ Globalsample( $n=695)$} & Age & 45.85 & $\mathrm{n} / \mathrm{a}$ & $\mathrm{n} / \mathrm{a}$ \\
\hline & Std. deviation of age & 15.42 & $\mathrm{n} / \mathrm{a}$ & $\mathrm{n} / \mathrm{a}$ \\
\hline & Ethnicity & Caucasian & 488 & $70.20 \%$ \\
\hline & Gender & Male & 417 & $60.00 \%$ \\
\hline & Education & 4-year college and advanced degrees & 520 & $74.80 \%$ \\
\hline & Income & $\$ 25,000$ to $\$ 75,000$ & 429 & $61.80 \%$ \\
\hline & Job & Employed (Full-time + part-time) & 570 & $82.00 \%$ \\
\hline \multirow[t]{7}{*}{ Young $(18-39)(n=264)$} & Age & 29.78 & $\mathrm{n} / \mathrm{a}$ & $\mathrm{n} / \mathrm{a}$ \\
\hline & Std. Deviation of Age & 4.08 & $\mathrm{n} / \mathrm{a}$ & $\mathrm{n} / \mathrm{a}$ \\
\hline & Ethnicity & Caucasian & 161 & $61.00 \%$ \\
\hline & Gender & Male & 189 & $71.60 \%$ \\
\hline & Education & 4-year college and advanced degrees & 219 & $82.90 \%$ \\
\hline & Income & $\$ 25,000$ to $\$ 75,000$ & 159 & $60.30 \%$ \\
\hline & Job & Employed (Full-time + part-time) & 253 & $95.80 \%$ \\
\hline \multirow[t]{7}{*}{ Middle aged(40-59)(n=234) } & Age & 46.74 & $\mathrm{n} / \mathrm{a}$ & $\mathrm{n} / \mathrm{a}$ \\
\hline & Std. deviation of age & 4.93 & $\mathrm{n} / \mathrm{a}$ & $\mathrm{n} / \mathrm{a}$ \\
\hline & Ethnicity & Caucasian & 152 & $65.00 \%$ \\
\hline & Gender & Male & 158 & $67.50 \%$ \\
\hline & Education & 4-year college and advanced degrees & 193 & $82.40 \%$ \\
\hline & Income & $\$ 25,000$ to $\$ 75,000$ & 154 & $65.80 \%$ \\
\hline & Job & Employed (Full-time + part-time) & 217 & $92.80 \%$ \\
\hline \multirow[t]{7}{*}{ Old $(60+)(n=197)$} & Age & 66.00 & $\mathrm{n} / \mathrm{a}$ & $\mathrm{n} / \mathrm{a}$ \\
\hline & Std. deviation of age & 4.50 & $\mathrm{n} / \mathrm{a}$ & $\mathrm{n} / \mathrm{a}$ \\
\hline & Ethnicity & Caucasian & 175 & $88.80 \%$ \\
\hline & Gender & Female & 127 & $64.50 \%$ \\
\hline & Education & 4-year college and advanced degrees & 108 & $54.80 \%$ \\
\hline & Income & $\$ 25,000$ to $\$ 75,000$ & 116 & $58.90 \%$ \\
\hline & Job & Employed (Full-time + part-time) & 100 & $50.80 \%$ \\
\hline
\end{tabular}

${ }^{\dagger}$ means were reported for continuous variables and modes were displayed for ordinal (e.g., income) or categorical variables (e.g., gender); n/a, not applicable.

income ranging from $\$ 25,000$ to $\$ 75,000$ as of 2019 . Additionally, more than $80 \%$ of the participants were employed as either a full-time or part-time employee. The pattern of demographics breakdown was mostly consistent across three age groups, except more female members $(64.5 \%)$ were identified in the older adult segment.

\section{Bayesian Analyses}

\section{Bayesian Significance Testing of Changes}

The global results of the Bayesian significance testing of changes (see Table 2) indicated that, although slight decreases of hours in participating in PA across all three intensity levels were observed (e.g., $\Delta$ _VPA_T $=-0.002, \Delta$ _VPA_T $=-0.060$, and $\Delta$ _VPA_T $=-0.084)$, the changes were not statistically significant. Nevertheless, more frequent VPA was found among the older adults $\left(\Delta \_\right.$VPA_D $\left.=0.023, p<0.05\right)$. This finding suggested that people across all age groups at least maintained their activity levels even after the COVID-19 lockdown despite several challenges for individuals in engaging physically active leisure. In contrast, the participants experienced higher levels of sitting time [ $\Delta \_S P A \_T=0.432, p<0.001$ with $95 \%$ posterior credible intervals $(\mathrm{CI})(0.255,0.610)]$ in general. Except for the middle-aged respondents, young adults $\left[\Delta \_S P A \_T=0.712, p<0.001,95 \%\right.$ CI $\left.(0.693,0.254)\right]$ and older adults [ $\Delta$ _SPA_T $=0.331, p<0.05,95 \%$ CI $(0.063,0.015)]$ had a significantly increased sitting time indicating an increased level of sedentary behavior during the lockdown.

A significant increase in healthy diet was found in general $\left(\Delta \_\right.$DQ_H $\left.=1.827, p<0.001\right)$. While all three age groups experienced significant increases in healthy eating, young adults experienced an increased consumption of unhealthy food [ $\Delta$ _DQ_UH $=1.402, p<0.05,95 \%$ CI $(2.810,0.007)]$ and older adults' unhealthy diet was decreased significantly [ $\Delta \_$DQ_UH $=-0.553, p<0.001,95 \%$ CI $\left.(-0.237,-0.870)\right]$. In terms of alcohol consumption, overall, there was a significant decrease [ $\Delta$ _Alcohol $=-0.188, p<0.001$, 95\% CI $(-0.106$, $-0.271)]$. This may be due to the significant decrease in alcohol consumption among young adults [ $\Delta$ _Alcohol $=-0.393$, $p<0.001,95 \%$ CI $(-0.244,-0.544)]$. There were no significant changes in smoking in terms of the number of smokers and dependency level across all three age groups.

When it comes to sleep quality, we found a significant increased overall sleep quality among young adults $\left[\Delta \_\right.$OSQ $=0.129, p<0.05,95 \%$ CI $\left.(0.245,0.013)\right]$ but a 
TABLE 2 | The significance of changes in health indicators by age groups using Bayesian $t$-tests.

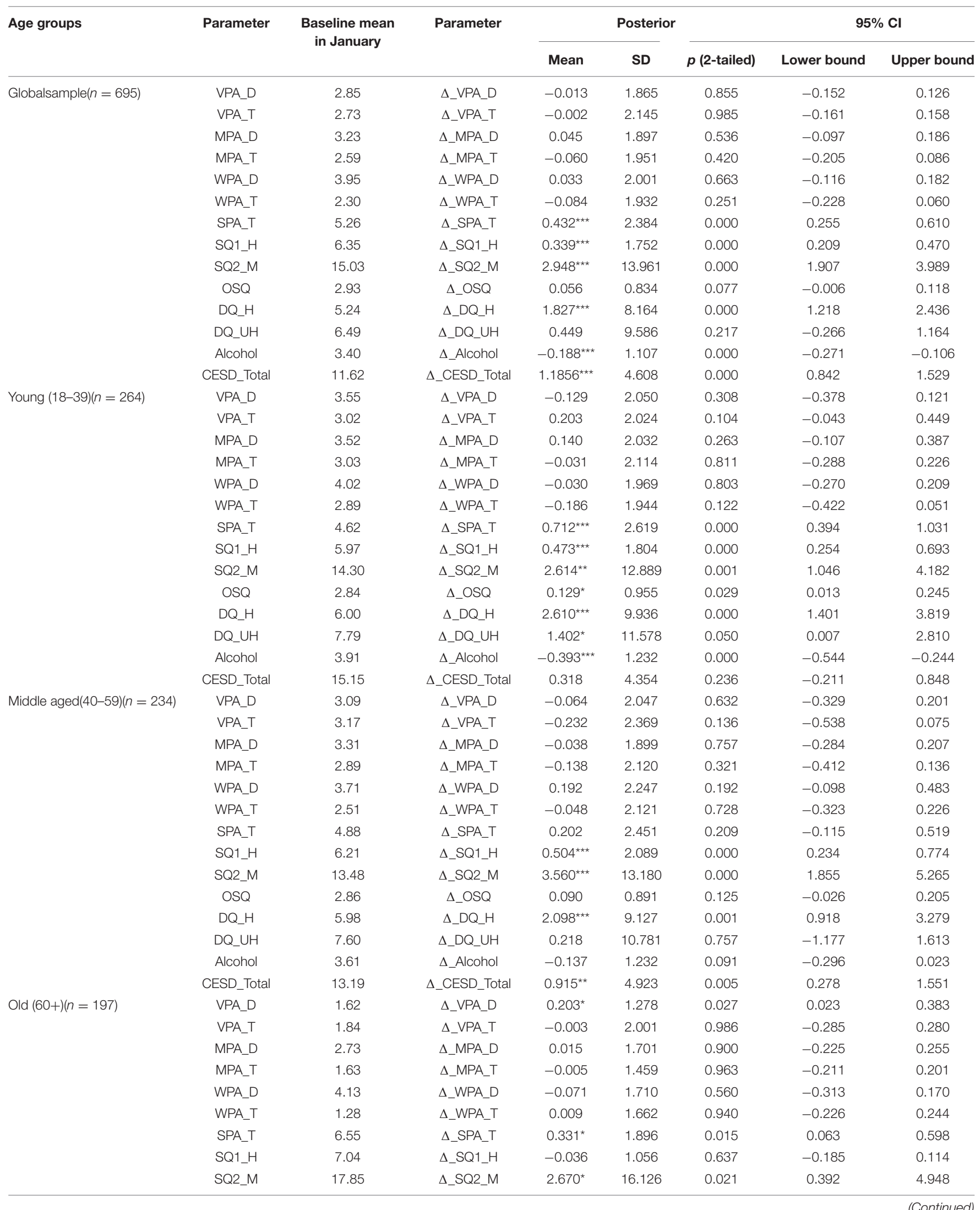


TABLE 2 | (Continued)

\begin{tabular}{|c|c|c|c|c|c|c|c|c|}
\hline \multirow[t]{2}{*}{ Age groups } & \multirow[t]{2}{*}{ Parameter } & \multirow{2}{*}{$\begin{array}{c}\text { Baseline mean } \\
\text { in January }\end{array}$} & \multirow[t]{2}{*}{ Parameter } & \multicolumn{3}{|c|}{ Posterior } & \multicolumn{2}{|c|}{$95 \% \mathrm{Cl}$} \\
\hline & & & & Mean & SD & $p$ (2-tailed) & Lower bound & Upper bound \\
\hline & OSQ & 3.11 & $\Delta \_\mathrm{OSQ}$ & $-0.081^{\star}$ & 0.519 & 0.029 & -0.154 & -0.008 \\
\hline & DQ_H & 3.34 & $\Delta \_D Q \_H$ & $0.457^{\star \star \star}$ & 1.307 & 0.000 & 0.272 & 0.641 \\
\hline & DQ_UH & 3.43 & $\Delta \_D Q \_U H$ & $-0.553^{\star \star \star}$ & 2.241 & 0.001 & -0.870 & -0.237 \\
\hline & Alcohol & 2.49 & $\Delta \_$Alcohol & 0.025 & 0.626 & 0.570 & -0.063 & 0.114 \\
\hline & CESD_Total & 5.01 & $\Delta$ _CESD_Total & $2.670^{\star \star \star}$ & 4.198 & 0.000 & 2.077 & 3.263 \\
\hline
\end{tabular}

Monte carlo sampling seed: 200,000 .

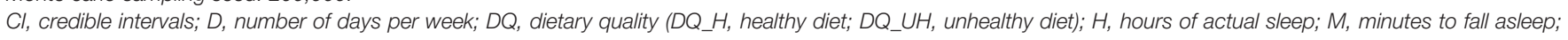

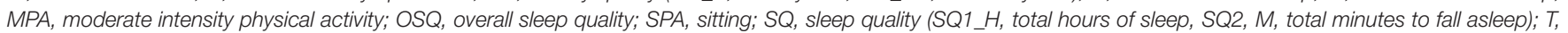
total time in hours on each day; VPA, vigorous intensity physical activity; WPA, walking.

${ }^{*} p<0.05 ;{ }^{* *} p<0.01$; and ${ }^{* * *} p<0.001$.

significant decreased overall sleep quality among older adults $\left[\Delta \_\right.$OSQ $=-0.081, p<0.05,95 \%$ CI $\left.(-0.008,-0.154)\right]$. This may be due to increased sleep time among young adults $\left[\Delta \_S Q 1 \_H=0.473, p<0.001,95 \%\right.$ CI $\left.(0.693,0.254)\right]$. The middle-aged respondents also slept longer $\left[\Delta_{-} \mathrm{SQ} 1 \_\mathrm{H}=0.504\right.$, $p<0.001,95 \%$ CI $(0.774,0.234)]$, but there was no significant change in overall sleep quality.

There was no significant change in DS among the younger participants whereas the middle-aged $\left[\Delta \_C E S D \_\right.$Total $=0.0 .915$, $p<0.01,95 \%$ CI $(1.551,0.278)]$ and older participants $\left[\Delta \_C E S D \_T o t a l=2.670, p<0.001,95 \%\right.$ CI $\left.(3.263,2.077)\right]$ had significantly higher levels of DS after the lockdown. As presented in Figure 2, the most of older adults experienced significantly increased levels of DS compared to younger and middle-aged adults.

\section{Bayesian Regression Analysis}

The results of Bayesian regression analysis (see Table 3 ) indicated that the difference in MPA_D $[\beta=-0.310, p<0.01,95 \%$ CI $(-0.500,-0.120)]$ and SPA_T $[\beta=0.160, p<0.01,95 \%$ CI $(0.030,0.290)]$ was significantly associated with differences in individuals' DS. Among the control variables, gender $[\beta=-1.050, p<0.01,95 \%$ CI $(-1.740,-0.360)]$, sleep latency $[\beta=0.07, p<0.001,95 \% \mathrm{CI}(0.05,0.09)]$, alcohol consumption $[\beta=0.38, p<0.05,95 \% \mathrm{CI}(0.08,0.68)]$, and smoking status $[\beta=-0.840, p<0.01,95 \%$ CI $(-1.580,-0.090)]$ were also significantly related with differences in the participants' DS. The effect size of the Bayesian regression model was adequate, and $17.1 \%$ of the variance in differences in DS was predicted by the proposed model. We further conducted a multi-group moderation analysis to examine if the relationships between differences in seven PA measures and differences in DS varied across the three age clusters.

Although young $[\beta=-1.25, p<0.01,95 \%$ CI $(-2.16$, $-0.35)]$ and middle-aged cohorts $[\beta=-0.88, p<0.05,95 \%$ CI $(-1.75,-0.001)]$ experienced significantly fewer differences in DS compared to their counterparts in the older group (see Table 2 and Figure 2), we found no significant heterogeneity effects in the relationships of interest between the age groups. For instance, despite increases in sitting time being significantly associated with a deteriorating difference in DS across all samples, the strength of the relationship was comparable between young and middle-aged groups $\left[\beta_{\text {diff }}=0.009, p=0.928,95 \% \mathrm{CI}(-0.010\right.$, $0.055)]$, young and older adult segments $\left[\beta_{\text {diff }}=-0.099\right.$, $p=0.305,95 \% \mathrm{CI}(-0.010,0.093)]$, and middle-aged and older clusters $\left[\beta_{\text {diff }}=-0.109, p=0.329,95 \%\right.$ CI $\left.(-0.083,0.083)\right]$. Similarly, there was no significant difference between differences of other measures of PA and differences in DS between young, middle-aged, and older adults.

\section{Robustness Checks With Machine Learning}

The visualizations of ROC curves corroborated with overall prediction accuracy based on confusion matrices indicated that both RF and SVM were able to significantly minimize the misclassification rate (Podsakoff et al., 2003). The overall classification accuracy (CA) was computed by using the total number of people correctly classified as depressed and undepressed, divided by a sum of four possible prediction outcomes (e.g., true depressed, true undepressed, false depressed, and false undepressed). In Figure 3, the orange curve refers to $\mathrm{RF}(\mathrm{CA}=99.50 \%)$, the purple curve represents support vector machines $(\mathrm{SVM})(\mathrm{CA}=97.4 \%)$, and the green curve reflects Naïve Bayes $(\mathrm{NB})(\mathrm{CA}=91.3 \%)$. Finally, Figure 4 presents the rankings of feature importance of the included behavioral and demographic correlates. The ranking of GD and IG indicated that Age_group, $\Delta \_S Q 1 \_H, \Delta \_S Q 2 \_M, \Delta \_D Q \_U H$, $\Delta$ _OSQ, $\Delta$ _MPA_D, $\Delta \_D Q \_H, \Delta \_A l c o h o l$, and $\Delta \_S P A \_T$ were consistently identified as the most critical behavioral and demographic attributes to positively impact the prediction results of classification, which were mostly consistent with the findings from the Bayesian regression analysis, thereby confirming the robustness of our results (see Figures 3, 4).

\section{DISCUSSION}

Several scholars have warned that social isolation guidelines from the COVID-19 pandemic can increase physical inactivity, which negatively impacts physical health (i.e., the immune system, respiratory system, cardiovascular system, and musculoskeletal system) (Woods et al., 2020) and mental 


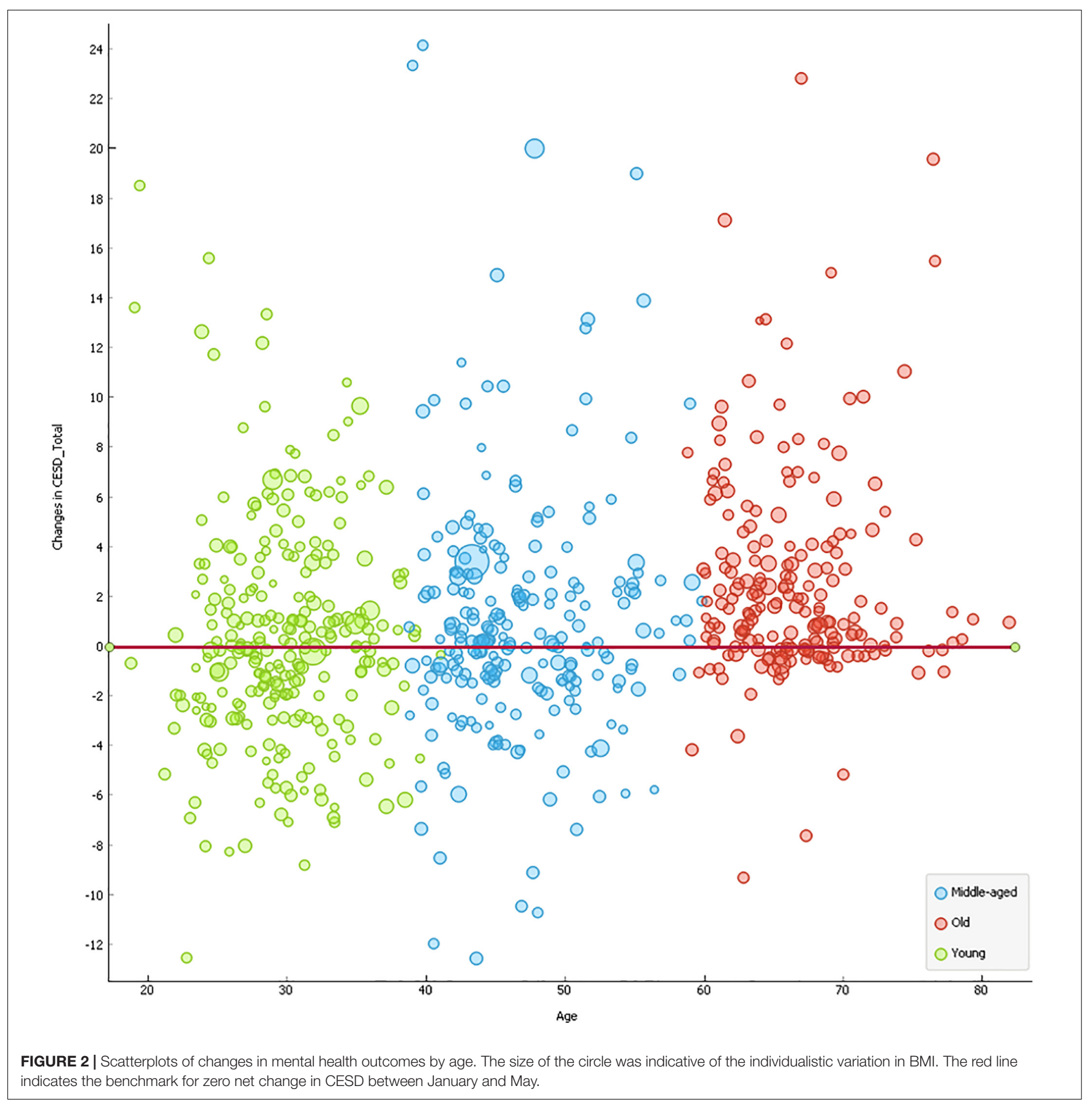

health (Pecanha et al., 2020). The primary aim of this study was to explore potential changes in levels of PA, NHB, and DS; and how changes in PA were associated with changes in one's DS among three different populations-young adults, middle-aged adults, and older adults - in the United States before (January of 2020) and after (May of 2020) the initiation of COVID-19-related social isolation guidelines.

The findings indicated that only the older adults' VPA frequency was significantly increased while all the other VPA, MPA, and WPA levels of the young, middle-aged, and older respondents were not significantly changed. On the contrary, significant increases in the levels of sedentary behavior (sitting time) were found, especially among the young and older respondents. These findings diverge from the results of previous studies. For instance, Lopez-Bueno et al. (2020) noticed weekly PA levels reduced by $20 \%$ during the first week of COVID19 lockdown in Spanish adults. Similarly, Yamada et al. (2020) found a significant decrease in total PA time among communitydwelling older adults in Japan. However, the inconsistency may be due to the fact that their study examined PA levels immediately 


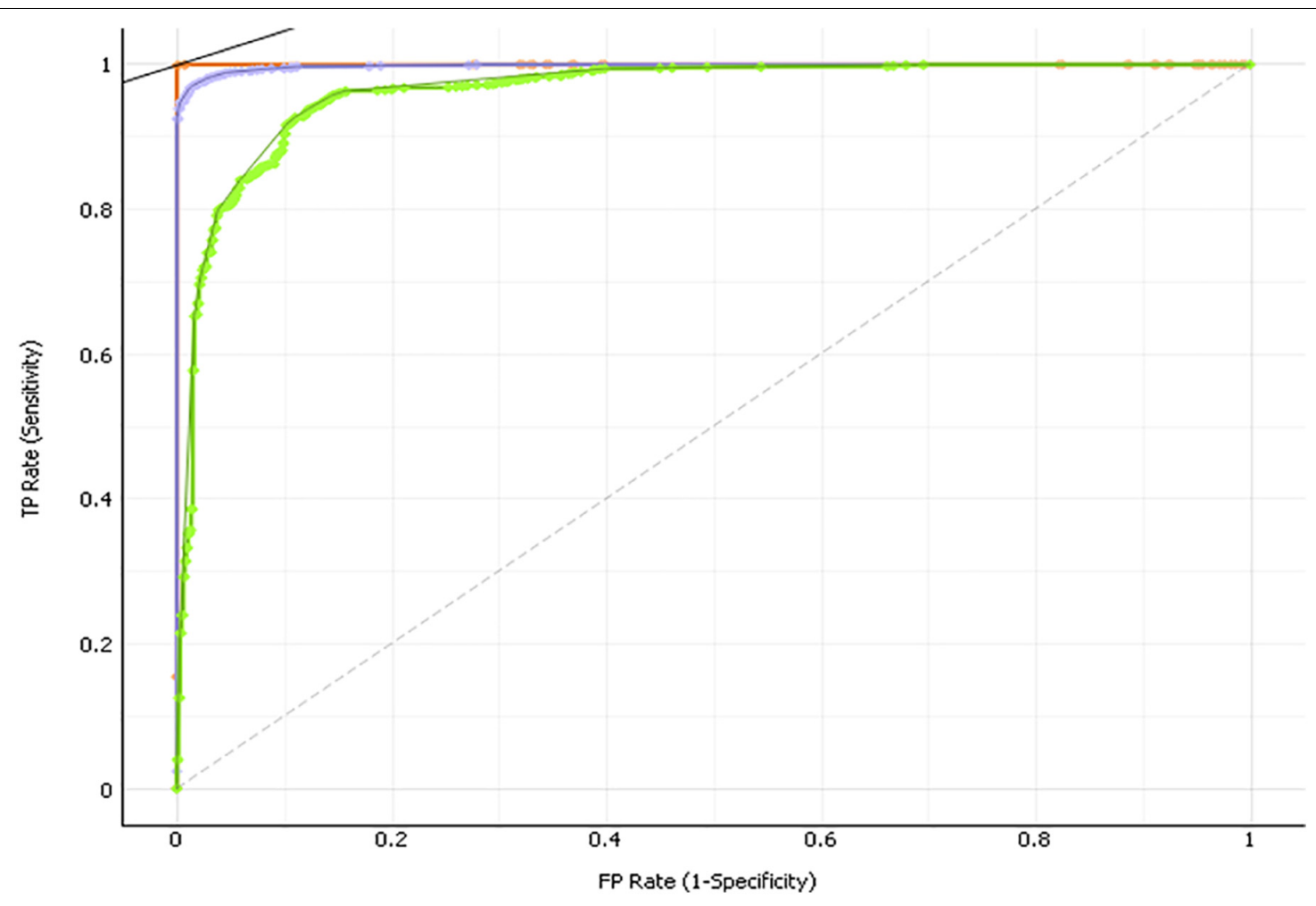

FIGURE 3 | Results of feature importance and ROC curves reflecting the predictive accuracy using machine learning.

after the confinement, which were in March of 2020 and April of 2020 respectively, whereas the current research examined PA levels in May of 2020. Possibly, the reduced PA levels reverted to the baseline level as the lockdown lasted more than a month.

The World Health Organization (WHO) recommends at least 150 min of MPA or 75 min of VPA per week, or a combination of both for adults, with a duration of $300 \mathrm{~min}$ of MPA for additional health benefits [World Health Organization (WHO), 2018]. It should be noted that, as of May of 2020, the study's participants reported an average of $466 \mathrm{~min}$ of VPA and $502 \mathrm{~min}$ of MPA per week. The older participants noted the lowest levels with an average of $178 \mathrm{~min}$ of VPA and $267 \mathrm{~min}$ of MPA per week, which still is higher than the WHO recommendations. This finding is somewhat consistent with Meyer et al. (2020) in that their United States samples also reported being at least sufficiently active across all three age groups in April of 2020. Unlike the PA levels, notably, the respondents-especially, young adults and older adults-experienced higher levels of sitting time during the lockdown. These findings are consistent with previous commentaries (e.g., Hall et al., 2020; Woods et al., 2020). Yet, even though there were few empirical studies on the changes of PA levels, no empirical studies on the changes of sedentary behavior have been published to date.

Despite the fact that several previous studies predicted a significant decrease in healthy diet and increase in unhealthy diet (Mattioli et al., 2020b), we found significant increases in healthy food consumption across all three groups, whereas only young adults had a significant increase in unhealthy food consumption.
The older adults even experienced a significant decrease in unhealthy food consumption. These relatively promising results may be due to the relatively high socioeconomic status of respondents. Moreover, since older COVID-19 patients tended to experience more significant health issues than their younger counterparts, older participants in the present study may have been more motivated to adopt positive lifestyle changes. The results of alcohol consumption also contradicted many previously published expectations (Mattioli et al., 2020a) since young respondents in our study reported significant decreases in alcohol consumption. Similarly, our finding of no changes in smoking levels and relapsing was also not congruent predicted behaviors (Patwardhan, 2020). Though respondents in the present study reported longer hours of sleep, they also noted more minutes were required to fall asleep after the lockdown, which was consistent with the results of prior research (Pinto et al., 2020; Wright et al., 2020).

Consistent with expectations (Purtle, 2020; Zandifar and Badrfam, 2020), the middle-aged and older participants had a significantly higher level of DS after the lockdown. Compared to the younger and middle-aged groups, particularly, the older respondents had significantly higher levels of DS after the lockdown as Figure 2 presented. This may seem alarming, but it should be noted that the baseline of the older participants' DS was well below the threshold (CESD_Total $=5.01$ ), whereas middle-aged $\left(C E S D \_T o t a l=13.19\right)$ and younger adults $($ CESD_Total $=15.15)$ showed mild levels of DS in January of 2020. In other words, even though the older adults were 


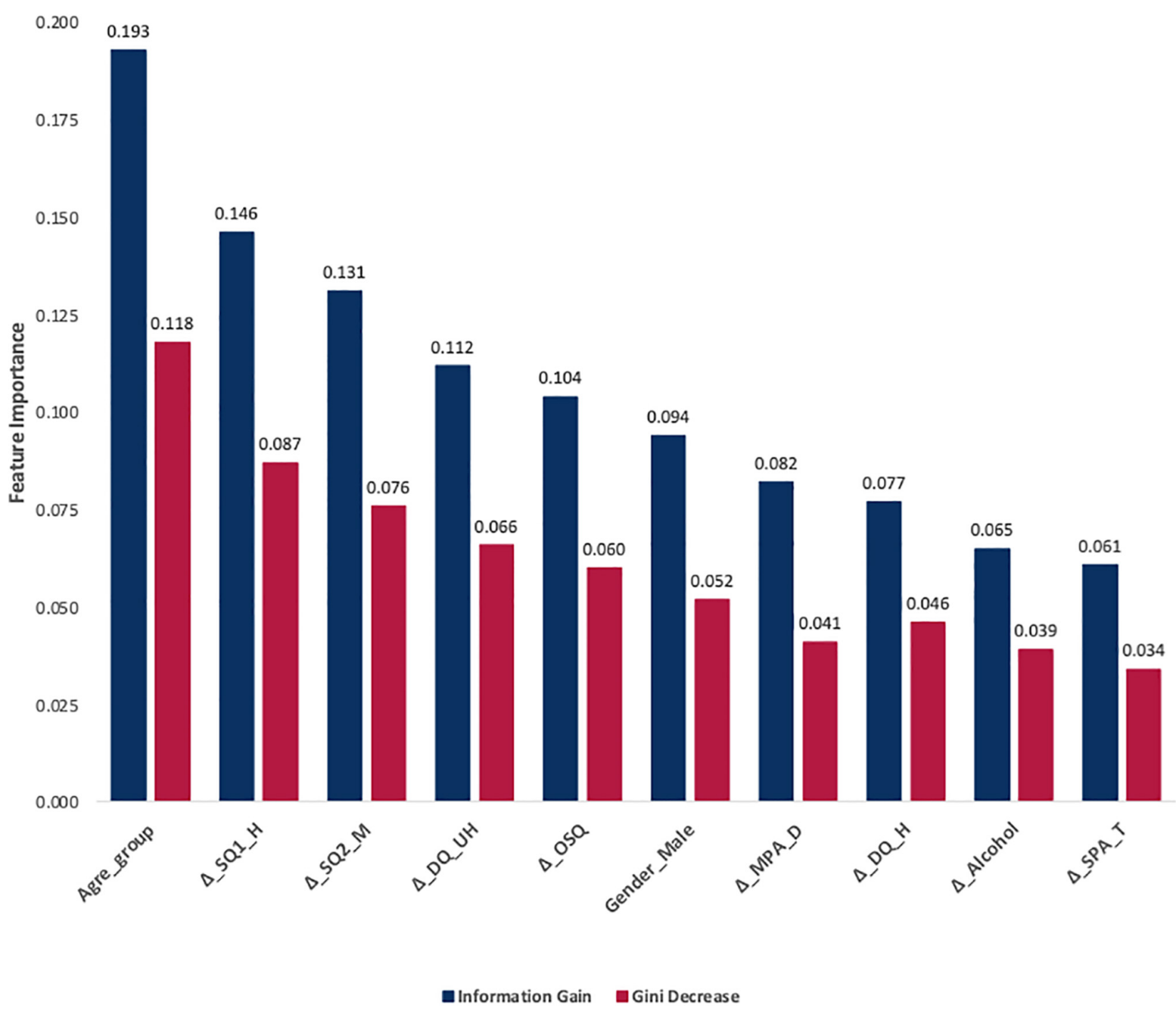

FIGURE 4 | Rankings of feature importance of the included behavioral and demographic correlates. Navy blue represents the ranking based on feature importance scores using Information Gain values. Glory red denotes the ranking based on feature importance scores based on Gini Decrease values.

experiencing more negative changes in DS, the group still had the lowest level of DS compared to the other counterparts in May of 2020. The findings support the previous studies on the relationship between aging and happiness in that happiness tends to decline from early adulthood to middle adulthood and turns back up as people age showing a U-shaped relationship (e.g., Frijters and Beatton, 2012; Graham and Ruiz Pozuelo, 2017).

After controlling NHB and personal characteristics, regardless of the age differences, the changes in frequency of MPA and sitting time were significantly associated with the changes in DS. Less frequent MPA and increased sitting time predicted a higher level of DS, a result consistent with previous studies (Mattioli et al., 2020a). In particular, the frequency of MPA, rather than the duration, mattered for DS. Considering that DS levels are assessed daily, more days with MPA may better combat DS than longer hours of doing MPA. Therefore, instead of combined minutes of PA, highlighting minimum days of PA may be even more important for mental health outcomes such as DS.
According to Rajkumar (2020), the research topics of published articles on the influence of COVID-19 on mental health have been very limited, including only observational studies on mental health symptoms in particular populations, commentary, and correspondence addressing the psychological impact of COVID-19 on the general populations, healthcare workers, and vulnerable populations. Consequently, there has been no intervention-based study to develop more therapeutic strategies and programs via active lifestyle to address mental health issues resulting from COVID-19, a necessary prerequisite of one's individual psychological well-being. For future intervention-based studies, it may be important to differentiate PA effects on mental health depending on the different levels of DS and different domains of PA (e.g., leisure-time PA, commuting PA, work-related PA; Appelqvist-Schmidlechner et al., 2020). In fact, few studies examined the relationship between exercise intensity and relief of depression through endorphin secretion. With moderate 
TABLE 3 | The results of Bayesian regression analysis of changes in physical activity on depressive symptoms.

\begin{tabular}{|c|c|c|c|c|c|}
\hline \multirow[t]{3}{*}{ Factors } & \multirow[t]{3}{*}{ Parameter } & \multicolumn{4}{|c|}{$\Delta$ in DS (Adjusted $R^{2}=17.1 \%$ ) } \\
\hline & & \multicolumn{2}{|c|}{ Posterior } & \multicolumn{2}{|c|}{$95 \% \mathrm{Cl}$} \\
\hline & & Mean & Variance & Lower bound & Upper bound \\
\hline & Intercept & $5.72^{\star \star}$ & 4.34 & 1.64 & 9.80 \\
\hline \multirow[t]{7}{*}{ Physical Activities } & $\Delta \_$VPA_D & -0.13 & 0.01 & -0.32 & 0.06 \\
\hline & $\Delta \_V P A \_T$ & 0.03 & 0.01 & -0.12 & 0.19 \\
\hline & $\Delta \_$MPA_D & $-0.31^{\star \star}$ & 0.01 & -0.50 & -0.12 \\
\hline & $\Delta \_M P A \_T$ & 0.03 & 0.01 & -0.14 & 0.21 \\
\hline & $\Delta \_$WPA_D & -0.02 & 0.01 & -0.19 & 0.14 \\
\hline & $\Delta \_$WPA_T & -0.10 & 0.01 & -0.27 & 0.07 \\
\hline & $\Delta \_$SPA_T & $0.16^{\star}$ & 0.00 & 0.03 & 0.29 \\
\hline \multirow[t]{11}{*}{ Personalcharacteristics } & Young & $-1.25^{\star \star}$ & 0.21 & -2.16 & -0.35 \\
\hline & Middle-aged & $-0.88^{\star}$ & 0.20 & -1.75 & -0.001 \\
\hline & Caucasian & -2.06 & 3.63 & -5.79 & 1.68 \\
\hline & African-American & -1.88 & 3.99 & -5.80 & 2.03 \\
\hline & Hispanic & -3.58 & 3.91 & -7.45 & 0.30 \\
\hline & Asian & -2.52 & 3.98 & -6.43 & 1.39 \\
\hline & Native American & -2.01 & 4.08 & -5.97 & 1.95 \\
\hline & Gender_Male & $-1.05^{\star \star}$ & 0.12 & -1.74 & -0.36 \\
\hline & Education & -0.20 & 0.03 & -0.51 & 0.11 \\
\hline & Income & -0.02 & 0.02 & -0.30 & 0.27 \\
\hline & $\mathrm{BMl}$ & 0.01 & 0.00 & -0.05 & 0.06 \\
\hline \multirow[t]{7}{*}{ Non-physical-activity health behaviors } & $\Delta \_S Q 1 \_H$ & -0.15 & 0.01 & -0.34 & 0.04 \\
\hline & $\Delta \_S Q 2 \_M$ & $0.07^{\star \star \star}$ & 0.00 & 0.05 & 0.09 \\
\hline & $\Delta_{-} \mathrm{OSQ}$ & -0.31 & 0.04 & -0.71 & 0.09 \\
\hline & $\Delta \_D Q \_H$ & 0.00 & 0.00 & -0.06 & 0.05 \\
\hline & $\Delta \_D Q \_U H$ & 0.02 & 0.00 & -0.03 & 0.07 \\
\hline & $\Delta \_$Alcohol & $0.38^{\star}$ & 0.02 & 0.08 & 0.68 \\
\hline & Smoke_Yes & $-0.84^{\star}$ & 0.15 & -1.58 & -0.09 \\
\hline
\end{tabular}

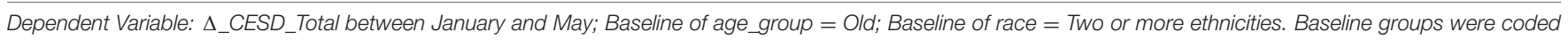
as zero in newly created dummy variables.

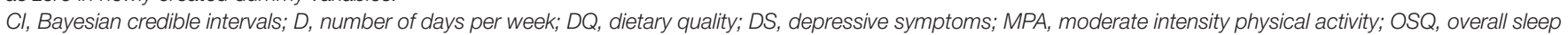
quality; SPA, sitting; SQ, sleep quality; T, total time in hours; VPA, vigorous intensity physical activity; WPA, walking.

${ }^{*} p<0.05 ;{ }^{* *} p<0.01$; and ${ }^{* * *} p<0.001$.

levels of depression, one study showed that only moderate- and high-intensity exercise could relieve depression levels of that magnitude (Balchin et al., 2016).

As social distancing policies continue due to the pandemic, various types of interventions should be newly developed to embrace the changing landscapes of social spaces. In order to provide resources in an easily accessible manner without any increase in infection risk, we need to consider technology-driven interventions for promoting an active lifestyle. Because digital technology offers more accessible resources, for instance, mobile health apps have been attractive to various populations due to their flexibility and ease of use (Anthes, 2016). To date, several studies have examined the effectiveness of mobile apps and wearable devices for PA promotion, but most studies have measured PA levels with simple step counts (Brickwood et al., 2019; Feter et al., 2019; Yerrakalva et al., 2019). Considering the results of the present study showed differing influences of PA on mental health depending on different levels and domains, more intervention studies should be conducted with an assessment that differentiates PA levels in the future.

Because the current study was an observational and exploratory study, employing the Bayesian approach provides several advantages compared to the conventional frequentist inferential statistics, which relies on the principle of long-run frequency and standard null-hypothesis significance-testing procedure (Trafimow, 2003). First, the Bayesian approach is suitable to integrate informative priors (e.g., individuals' baseline health conditions prior to the outbreak of the COVID-19 pandemic in January) into empirical probabilistic models (Gelman, 2004). Moreover, this approach does not require the asymptotic assumptions (i.e., multi-normality based on large samples) and is less computationally demanding (Kaplan, 2014). Lastly, the conclusions of Bayesian analyses are less sensitive to outliers and missing data, more robust to handle small sample sizes, and easier to interpret with the intuitive predictive posterior 
credible intervals (Rupp et al., 2004). Based on the results of exploratory studies like the current research, future studies from a deductive approach to examine the unintended longterm consequences of the COVID-19 pandemic by leveraging cumulative longitudinal data are needed.

\section{Limitations and Future Implications}

Our study included a number of limitations that have implications for future research. First, our convenience sample of United States residents featured a relatively healthy population with high levels of PA, low levels of DS, and an average or higher socioeconomic status. Accordingly, our results should not be generalized to dissimilar populations. Second, we included sociodemographic information, BMI, and NHB as covariates, but there may be other major variables that may significantly influence one's PA level and DS. For instance, in the field of social epidemiology (i.e., an academic field interested in the impacts of social factors on health and disease distribution in populations; El-Sayed et al., 2012), previous studies found that online social networking may impact the spread of non-infectious conditions such as smoking, alcohol consumption, tobacco use, or physical (in)activity (Maher et al., 2014). These factors related to social media consumption and website usage may need to be considered in future PA and DS studies. Additionally, we asked participants to recall their behavior 5 months ago. Considering that COVID19 is a historical and impactful global event for every person, it is reasonable to expect more people would remember their behaviors and moods around the event. Nevertheless, recall bias can be a concern for this type of cross-sectional data. Lastly, high levels of PA among our respondents may be due to the impact of social desirability on self-report PA questionnaire, a possibility that cannot entirely be ruled out (Crutzen and Göritz, 2011; Brenner and DeLamater, 2014).

\section{REFERENCES}

Alcohol Change UK (2020). Research: Drinking in the UK During Lockdown and Beyond. Available online at: https://alcoholchange.org.uk/blog/2020/drinkingin-the-uk-during-lockdown-and-beyond (accessed January 2, 2021).

Andresen, E. M., Malmgren, J. A., Carter, W. B., and Patrick, D. L. (1994). Screening for depression in well older adults: evaluation of a short form of the CES-D. Am. J. Prevent. Med. 10, 77-84. doi: 10.1016/S0749-3797(18)30622-6

Anthes, E. (2016). Mental health: there's an app for that. Nature 532, 20-23. doi: $10.1038 / 532020 \mathrm{a}$

Appelqvist-Schmidlechner, K., Vaara, J. P., Vasankari, T., Hakkinen, A., Mantysaari, M., and Kyrolainen, H. (2020). Relationship between different domains of physical activity and positive mental health among young adult men. BMC Public Health 20:1116. doi: 10.1186/s12889-020-09175-6

Baker, B. J., Du, J., Sato, M., and Funk, D. C. (2019). Rethinking segmentation within the psychological continuum model using Bayesian analysis. Sport Manag. Rev. 23, 764-775. doi: 10.1016/j.smr.2019.09.003

Balchin, R., Linde, J., Blackhurst, D., Rauch, H. L., and Schonbachler, G. (2016). Sweating away depression? The impact of intensive exercise on depression. J. Affect. Disord. 200, 218-221. doi: 10.1016/j.jad.2016.04.030

Banerjee, D., and Rai, M. (2020). Social isolation in COVID-19: the impact of loneliness. Intern. J. Soc. Psychiatry 66, 525-527. doi: 10.1177/0020764020922269

Barry, A. E., Chaney, B. H., Stellefson, M. L., and Dodd, V. (2015). Evaluating the psychometric properties of the AUDIT-C among college students. J. Substance Use 20, 1-5. doi: 10.3109/14659891.2013.856479
Finally, several studies have noted that existing health inequalities may be amplified as a consequence of the COVID19 lockdown. For example, Lopez-Bueno et al. (2020) found a stronger effect of PA reduction ingroups with lower education. Considering that the majority of the present sample tended to have relatively high socioeconomic status (e.g., higher education, higher employment rate), further studies with underrepresented populations should be conducted to grasp a more complete picture of the effect of the COVID-19 lockdown on the public.

\section{DATA AVAILABILITY STATEMENT}

The original contributions presented in the study are included in the article/supplementary material, further inquiries can be directed to the corresponding author.

\section{ETHICS STATEMENT}

The studies involving human participants were reviewed and approved by Florida State University. The patients/participants provided their written informed consent to participate in this study.

\section{AUTHOR CONTRIBUTIONS}

$\mathrm{AK}, \mathrm{JD}$, and DA contributed to the conception and design of the study and wrote sections of the manuscript. AK organized the data collection. JD performed the statistical analyses. All authors contributed to manuscript revision, read, and approved the submitted version.

Björgvinsson, T., Kertz, S. J., Bigda-Peyton, J. S., McCoy, K. L., and Aderka, I. M. (2013). Psychometric properties of the CES-D 10 in a psychiatric sample. Assessment 20, 429-436. doi: 10.1177/1073191113481998

Blume, C., Schmidt, M. H., and Cajochen, C. (2020). Effects of the COVID-19 lockdown on human sleep and rest-activity rhythms. Curr. Biol. 30, R783-R801. doi: 10.1016/j.cub.2020.06.021

Bradley, K. A., DeBenedetti, A. F., Volk, R. J., Williams, E. C., Frank, D., and Kivlahan, D. R. (2007). AUDIT-C as a brief screen for alcohol misuse in primary care. Alcoh. Clin. Exper. Res. 31, 1208-1217. doi: 10.1111/j.1530-0277.2007. 00403.x

Breiman, L. (2001). Random forests. Mach. Learn. 45, 5-32. doi: 10.1023/A: 1010933404324

Brenner, P. S., and DeLamater, J. D. (2014). Social desirability bias in self-reports of physical activity: is an exercise identity the culprit? Soc. Indic. Res. 117, 489-504. doi: 10.1007/s11205-013-0359-y

Brickwood, K.-J., Watson, G., O’Brien, J., and Williams, A. D. (2019). Consumerbased wearable activity trackers increase physical activity participation: systematic review and meta-analysis. JMIR Mhelath Uhealth 7:e11819. doi: $10.2196 / 11819$

Bush, K., Kivlahan, D. R., McDonell, M. B., Fihn, S. D., and Bradley, K. A. (1998). The AUDIT alcohol consumption questions (AUDIT-C): an effective brief screening test for problem drinking. Archiv. Intern. Med. 158, 1789-1795. doi: 10.1001/archinte.158.16.1789

Buysse, D. J., Reynolds, C. F., Monk, T. H., Berman, S. R., and Kupfer, D. J. (1989). The pittsburgh sleep quality index: a new instrument for psychiatric practice and research. Psychiatry Res. 28, 193-213. doi: 10.1016/0165-1781(89)90047-4 
Callow, D. D., Arnold-Nedimala, N. A., Jorda, L. S., Pena, G. S., WOn, J., Woodard, J. L., et al. (2020). The mental health benefits of physical activity in older adults survive the COVID-19 pandemic. Am. J. Geriatr. Psychiat. doi: 10.1016/j.jagp. 2020.06.024

Carpenter, J. S., and Andryknowski, M. A. (1998). Psychometric evaluation of the pittsburgh sleep quality index. J. Psychosom. Res. 45, 5-13. doi: 10.1016/S00223999(97)00298-5

CGA (2020). Britain's Drinking Habits are Changing Under Lockdown. Available online at: https://www.cga.co.uk/2020/04/03/britains-drinking-habits-arechanging-under-lockdown/ (accessed January 2, 2021).

Crutzen, R., and Göritz, A. S. (2011). Does social desirability compromise selfreports of physical activity in web-based research? Intern. J. Behav. Nutrit. Phys. Activ. 8:31. doi: 10.1186/1479-5868-8-31

DiGiovanni, C., Conley, J., Chiu, D., and Zaborsk, J. (2003). Factors influencing compliance with quarantine in Toronto during the 2003 SARS outbreak. Biosecur. Bioterr. 2, 265-272. doi: 10.1089/bsp.2004.2.265

Du, J., Floyd, C., Kim, A. C. H., Baker, B. J., Sato, M., James, J. D., et al. (2021). To be or not to be: Negotiating leisure constraints with technology and data analytics amid the COVID-19 pandemic. Leisure Stud. 40, 561-574. doi: 10. 1080/02614367.2020.1862284

Eigenschenk, B., Thomann, A., McClure, M., Davies, L., Gregory, M., Dettweiler, U., et al. (2019). Benefits of outdoor sports for society: a systematic review and reflections on evidence. Intern. J. Environ. Res. Public Health 16:937. doi: 10.3390/ijerph16060937

Elassar, A. (2020). This is Where Each State is During its Phased Reopening. Available online at: https://www.cnn.com/interactive/2020/us/states-reopencoronavirus-trnd/ (accessed January 2, 2021).

El-Sayed, A. M., Scarborough, P., Seemann, L., and Galea, S. (2012). Social network analysis and agent-based modeling in social epidemiology. Epidemiol. Perspect. Innov. 9:1. doi: 10.1186/1742-5573-9-1

Feter, N., dos Santos, T. S., Caputo, E. L., and da Silva, M. C. (2019). What is the role of smartphones on physical activity promotion? A systematic review and meta-analysis. Intern. J. Public Health 64, 679-690. doi: 10.1007/s00038-01901210-7

Frayer, C. D., Ostchega, Y., Hales, C. M., Zhang, G., and Kruszon-Moran, D. (2017). Hypertension Prevalence And Control Among Adults: United States, 20152016. Available online at: https://www.cdc.gov/nchs/data/databriefs/db289.pdf (accessed January 2, 2021).

Frijters, P., and Beatton, T. (2012). The mystery of the U-shaped relationship between happiness and age. J. Econ. Behav. Organ. 82, 525-542.

Fu, W., Wang, C., Zou, L., Guo, Y., Lu, Z., Yan, S., et al. (2020). Psychological health, sleep quality, and coping styles to stress facing the COVID-19 in Wuhan China. Transl. Psychiatry 10:225. doi: 10.1038/s41398-020-00913-3

Fukukawa, Y., Nakashima, C., Tsuboi, S., Kozakai, R., Doyo, W., Niino, N., et al. (2004). Age differences in the effect of physical activity on depressive symptoms. Psychol. Aging 19, 346-351. doi: 10.1037/0882-7974.19.2.346

Gelman, A. (2004). Parameterization and Bayesian modeling. J. Am. Statist. Assoc. 99, 537-545. doi: 10.1198/016214504000000458

Golechha, M. (2020). COVID-19, India, lockdown and psychosocial challenges: What's next? Intern. J. Soc. Psychiatry 66, 830-832. doi: 10.1177/0020764 020935922

Graham, C., and Ruiz Pozuelo, J. (2017). Happiness, stress, and age: how the U curve varies across people and places. J. Popul. Econ. 30, 225-264.

Grandner, M. A., Kripke, D. F., Yoon, I.-Y., and Youngstedt, S. D. (2006). Criterion validity of the pittsburgh sleep quality index: investigation in a non-clinical sample. Sleep Biol. Rhythms 4, 129-136. doi: 10.1111/j.1479-8425.2006.00207.x

Grippo, A. J., Lamb, D. G., Carter, C. S., and Porges, S. W. (2007). Social isolation disrupts autonomic regulation of the heart and influences negative affective behaviors. Biol. Psychiatry 62, 1162-1170. doi: 10.1016/j.biopsych.2007.04.011

Hall, G., Laddu, D. R., Phillips, S. A., Lavie, C. J., and Arena, R. (2020). A tale of two pandemics: How will COVID-19 and global trends in physical inactivity and sedentary behavior affect one another? Prog. Cardiovasc. Dis. 64, 108-110. doi: 10.1016/j.pcad.2020.04.005

Hammami, A., Harrabi, B., Mohr, M., and Krustrup, P. (2020). Physical activity and coronavirus disease 2019 (COVID-19): specific recommendations for homebased physical training. Manag. Sport Leisure (in press). doi: 10.1080/23750472. 2020.1757494
Hauser, D. J., and Schwarz, N. (2016). Attentive Turkers: MTurk participants perform better on online attention checks than do subject pool participants. Behav. Res. Methods 48, 400-407. doi: 10.3758/s13428-015-0578-z

Hawryluck, L., Gold, W. L., Robinson, S., Pogorski, S., Galea, S., and Styra, R. (2004). SARS control and psychological effects of quarantine, Toronto, Canada. Emerg. Infect. Dis. 10, 1206-1212. doi: 10.3201/eid1007.030703

Heatherton, T. F., Kozlowski, L. T., Frecker, R. C., and Fagerstrom, K. O. (1991). The fagerstrom test for nicotine dependence: a revision of the Fagerstrom tolerance questionnaire. Br. J. Addict. 86, 1119-1127. doi: 10.1111/j.1360-0443. 1991.tb01879.x

Hudmon, K. S., Pomerleau, C. S., Brigham, J., Javitz, H., and Swan, G. E. (2005). Validity of retrospective assessments of nicotine dependence: a preliminary report. Addict. Behav. 30, 613-617. doi: 10.1016/j.addbeh.2004.08.006

Islam, N., Sharp, S. J., Chowell, G., Shabnam, S., Kawachi, I., Lacey, B., et al. (2020). Physical distancing interventions and incidence of coronavirus disease 2019: Natural experiment in 149 countries. BMJ 370:m2743. doi: 10.1136/bmj.m2743

Jimenez-Pavon, D., Carbonell-Baeza, A., and Lavie, C. J. (2020). Physical exercise as therapy to fight against the mental and physical consequences of COVID-19 quarantine: Special focus in older people. Prog. Cardiovasc. Dis. 63, 386-388. doi: 10.1016/j.pcad.2020.03.009

Kaplan, D. (2014). Bayesian Statistics for the Social Sciences. New York, NY: Guilford Publications.

Lee, P. H., Macfarlane, D. J., Lam, T. H., and Stewart, S. M. (2011). Validity of the international physical activity questionnaire short form (IPAQ-SF): a systematic review. Intern. J. Behav. Nutr. Phys. Activ. 8:115. doi: 10.1186/1479-58688-115

Lee, S., Chan, L. Y., Chau, A. M., Kwok, K. P., and Kleinman, A. (2005). The experience of SARS-related stigma at amoy gardens. Soc. Sic. Med. 61, 20382046. doi: 10.1016/j.socscimed.2005.04.010

Lopez-Bueno, R., Calatayud, J., Andersen, L. L., Balsalobre-Fernandez, C., Casana, J., Casajus, J. A., et al. (2020). Immediate impact of the COVID-19 confinement on physical activity levels in Spanish adults. Sustainability 12:5708. doi: 10.3390/ su12145708

Loucks, E. B., Berkman, L. F., Gruenewald, T. L., and Seeman, T. E. (2006). Relation of social integration to inflammatory marker concentrations in men and women 70 to 79 years. Am. J. Cardiol. Prevent. Cardiol. 97, 1010-1016. doi: 10.1016/j.amjcard.2005.10.043

Maher, C. A., Lewis, L. K., Ferrar, K., Marshall, S., De Bourdeaudhuij, I, and Vandelanotte, C. (2014). Are health behavior change itnerventions that use online social networks effective? a systematic review. J. Med. Internet. Res. 16:e40. doi: 10.2196/jmir.2952

Mason, W., and Suri, S. (2012). Conducting behavioral research on Amazon's Mechanical Turk. Behav. Res. Methods 44, 1-23. doi: 10.3758/s13428-0110124-6

Mattioli, A. V., Puviani, M. B., Nasi, M., and Farinetti, A. (2020a). A COVID-19 pandemic: The effects of quarantine on cardiovascular risk. Eur. J. Clin. Nutr. 74, 852-855. doi: 10.1038/s41430-020-0646-z

Mattioli, A. V., Sciomer, S., Cocchi, C., Maffei, S., and Gallina, S. (2020b). Quarantine during COVID-19 outbreak: changes in diet and physical activity increase the risk of cardiovascular disease. Nutr. Metab. Cardiovasc. Dis. 30, 1409-1417. doi: 10.1016/j.numecd.2020.05.020

Meyer, J., Herring, M., McDowell, C., Lansing, J., Brower, C., Schuch, F., et al. (2020). Joint prevalence of physical activity and sitting time during COVID19 among US adults in April 2020. Prevent. Med. Rep. 20:101256. doi: 10.1016/ j.pmedr.2020.101256

Mohebbi, M., Nguyen, V., McNeil, J. J., Woods, R. L., Nelson, M. R., Shah, R. C., et al. (2018). Psychometric properties of a short form of the Center for Epidemiologic Studies Depression (CES-D-10) scale for screening depressive symptoms in healthy community dwelling older adults. Gen. Hosp. Psychiatry 51,118-125. doi: 10.1016/j.genhosppsych.2017.08.002

Mortensen, K., and Hughes, T. L. (2018). Comparing Amazon's Mechanical Turk platform to conventional data collection methods in the health and medical research literature. J. Gen. Intern. Med. 33, 533-538. doi: 10.1007/s11606-0174246-0

Noh, J.-W., Kwon, Y. D., and Kim, J. (2015). Body mass index and depressive symptoms in middle aged and older adults. BMC Public Health 15:310. doi: 10.1186/s12889-015-1663-z 
Oftedal, S., Kolt, G. S., Holliday, E. G., Stamatakis, E., Vandelanotte, C., Brown, W. J., et al. (2019). Associations of health-behavior patterns, mental health and self-rated health. Prevent. Med. 118, 295-303. doi: 10.1016/j.ypmed.2018.11.017

Patwardhan, P. (2020). COVID-19: Risk of increase in smoking rates among England's 6 million smokers and relapse among England's 11 million exsmokers. BJGP Open 4:bjoen20X101067. doi: 10.3399/bjgpopen20X101067

Pecanha, T., Goessler, K. F., Roschel, H., and Gualano, B. (2020). Social isolation during the COVID-19 pandemic can increase physical inactivity and the global burden of cardiovascular disease. Am. J. Physiol. 318, H1441-H1446. doi: 10. 1152/ajpheart.00268.2020

Pelizza, L., and Pupo, S. (2020). COVID-19 epidemic and public mental health care in Italy: ethical considerations. Soc. Psychiatry Psychiatr. Epidemiol. 55, 1093-1094. doi: 10.1007/s00127-020-01907-8

Pfefferbaum, B., and North, C. S. (2020). Mental health and the COVID-19 pandemic. New Engl. J. Med. 383, 510-512. doi: 10.1056/NEJMp2008017

Pinto, J., van Zeller, M., Amorim, P., Pimentel, A., Dantas, P., Eusebio, E., et al. (2020). Sleep quality in times of COVID-19 pandemic. Sleep Med. 74, 81-85. doi: 10.1016/j.sleep.2020.07.012

Podsakoff, P. M., MacKenzie, S. B., Lee, J. Y., and Podsakoff, N. P. (2003). Common method biases in behavioral research: a critical review of the literature and recommended remedies. J. Appl. Psychol. 88, 879-903. doi: 10.1037/0021-9010. 88.5.879

Purtle, J. (2020). COVID-19 and mental helath equity in the United States. Soc. Psychiatry Psychiatr. Epidemiol. 55, 969-971. doi: 10.1007/s00127-020-01896-8

Putt, A. (2020). New York Issues a 'Pause' on Nonessential Services and Gatherings: Here's What That Means. Available online at: https://ny.curbed.com/2020/ 3/20/21187022/coronavirus-new-york-shutdown-shelter-in-place (accessed January 2, 2021).

Rajkumar, R. P. (2020). COVID-19 and mental health: a review of existing literature. Asian J. Psychiatry 52:102066. doi: 10.1016/j.ajp.2020.102066

Ranard, B. L., Ha, Y. P., Meisel, Z. F., Asch, D. A., Hill, S. S., Becker, L. B., et al. (2014). Crowdsourcing - harnessing the masses to advance health and medicine. J. Gen. Intern. Med. 29, 187-203. doi: 10.1007/s11606-013-2536-8

Roberts, K. (2020). Locked down leisure in Britain. Leisure Stud. 39, 1-12. doi: 10.1080/02614367.2020.1791937

Rouse, S. V. (2015). A realibility analysis of mechanical Turk data. Comput. Hum. Behav. 43, 304-307. doi: 10.1016/j.chb.2014.11.004

Rupp, A. A., Dey, D. K., and Zumbo, B. D. (2004). To Bayes or not to Bayes, from whether to when: applications of Bayesian methodology to modeling. Struct. Equ. Model. 11, 424-451. doi: 10.1207/s15328007sem1103_7

Schaefer, L., Plotnikoff, R. C., Majumdar, S. R., Mollard, R., Woo, M., Sadman, R., et al. (2014). Outdoor time is associated with physical activity, sedentary time, and cardiorespiratory fitness in youth. J. Pediatr. 165, 516-521. doi: 10.1016/j. jpeds.2014.05.029

Shigemura, J., Ursano, R. J., Morganstein, J. C., Kurosawa, M., and Benedek, D. M. (2020). Public responses to the novel 2019 coronavirus (2019-cCOV) in Japan: Mental health consequences and target populations. Psychiatry Clin. Neurosci. 74, 281-282. doi: 10.1111/pcn.12988

Sleep Foundation (2020). Sleep Guidelines during the COVID-19 Pandemic. Available online at: https://www.sleepfoundation.org/sleep-guidelines-covid19-isolation (accessed January 2, 2021).

Smith, N. A., Sabat, I. E., Martinez, L. R., Weaver, K., and Xu, S. (2015). A convenient solution: Using MTurk to sample from hard-to-reach populations. Industr. Organ. Psychol. 8, 220-228. doi: 10.1017/iop.2015.29

Steinwart, I., and Christmann, A. (2008). Support Vector Machines. New York, NY: Springer-Verlag New York.

Stephens, T. (1988). Physical activity and mental health in the United States and Canada: Evidence from four population surveys. Prevent. Med. 17, 35-47. doi: 10.1016/0091-7435(88)90070-9
Sturtz, S., Liggers, U., and Gelman, A. (2005). R2WinBUGS: A Package for Running WinBUGS from R. Available online at: https://cran.r-project.org/web/packages/ R2WinBUGS/vignettes/R2WinBUGS.pdf (accessed January 2, 2021).

Trafimow, D. (2003). Hypothesis testing and theory evaluation at the boundaries: Surprising insights from Bayes's theorem. Psychol. Rev. 110, 526-535. doi: 10. 1037/0033-295X.110.3.526

United Nations (2020). The Impact of COVID-19 on Sport, Physical Activity and Well-Being and its Effects on Social Development. Available online at: https://www.un.org/development/desa/dspd/wp-content/uploads/sites/22/ 2020/05/PB_73.pdf (accessed January 2, 2021).

Wang, C., Pan, R., Wan, X., Tan, Y., Xu, L., and Ho, C. S. (2020). Immediate psychological responses and associated factors during the initial stage of the 2019 coronavirus disease (COVID-19) epidemic among the general population in China. Intern. J. Environ. Res. Public Health 17:E1729. doi: 10.3390/ ijerph17051729

Wolanin, A., Hong, E., Marks, D., Panchoo, K., and Gross, M. (2016). Prevalence of clinically elevated depressive symptoms in college athletes and differences by gender and sport. Br. J. Sports Med. 50, 167-171. doi: 10.1136/bjsports-2015095756

Woods, J. A., Hutchinson, N. T., Powers, S. K., Roberts, W. O., GomezCabrera, M. C., Radak, Z., et al. (2020). The COVID-19 pandemic and physical activity. Sport Med. Health Sci. 2, 55-64. doi: 10.1016/j.smhs.2020. 05.006

World Health Organization (WHO) (2018). Physical Activity. Available online at: https://www.who.int/news-room/fact-sheets/detail/physical-activity (accessed January 2, 2021).

Wright, K. P. Jr., Linton, S. K., Withrow, D., Casiraghi, L., Lanza, S. M., de la Iglesia, H., et al. (2020). Sleep in university students prior to and during COVID19 stay-at home orders. Curr. Biol. 20, R783-R801. doi: 10.1016/j.cub.2020. 06.022

Yamada, M., Kimura, Y., Ishiyama, D., Otobe, Y., Suzuki, M., Koyama, S., et al. (2020). Effect of the COVID-19 epidemic on physical activity in community dwelling older adults in Japan: a cross-sectional online survey. J. Nutr. Health Aging 24, 948-950. doi: 10.1007/s12603-020-1424-2

Yerrakalva, D., Yerrakalva, D., Hajna, S., and Griffin, S. (2019). Effects of mobile health app interventions on sedentary time, physical activity, and fitness in older adults: systematic review and meta-analysis. J. Med. Internet Res. 21:e14343. doi: 10.2196/14343

Zandifar, A., and Badrfam, R. (2020). Iranian mental helath during the COVID-19 epidemic. Asian J. Psychiatry 51:101990.

Zylla, E., and Hartman, L. (2020). State COVID-19 Data Dashboards. Available online at: https://www.shvs.org/state-covid-19-data-dashboards/

Conflict of Interest: The authors declare that the research was conducted in the absence of any commercial or financial relationships that could be construed as a potential conflict of interest.

Publisher's Note: All claims expressed in this article are solely those of the authors and do not necessarily represent those of their affiliated organizations, or those of the publisher, the editors and the reviewers. Any product that may be evaluated in this article, or claim that may be made by its manufacturer, is not guaranteed or endorsed by the publisher.

Copyright (C) $2022 \mathrm{Kim}, \mathrm{Du}$ and Andrew. This is an open-access article distributed under the terms of the Creative Commons Attribution License (CC BY). The use, distribution or reproduction in other forums is permitted, provided the original author(s) and the copyright owner(s) are credited and that the original publication in this journal is cited, in accordance with accepted academic practice. No use, distribution or reproduction is permitted which does not comply with these terms. 